\title{
Extending the Indications of 5-Aminolevulinic Acid for Fluorescence-Guided Surgery for Different Central Nervous System Tumors: A Series of 255 Cases in Latin America
}

\section{Ampliando as indicações de ácido 5-aminolevulínico em cirugia guiada por fluorescência para diferentes tumores do sistema nervoso central: Uma série de 255 casos na América Latina}

\author{
Erasmo Barros da Silva Jr ${ }^{10}$ Ricardo Ramina ${ }^{1}$ Maurício Coelho Neto ${ }^{1}$ \\ Guilherme Augusto de Souza Machado ${ }^{1}$ Marcella Santos Cavalcanti2 ${ }^{2}$ Joseph Franklin Chenisz da Silva ${ }^{1(0)}$ \\ ${ }^{1}$ Department of Neurosurgery, Section of Neuro-oncology, Instituto \\ Address for correspondence Erasmo Barros da Silva Jr, MD, MSc, \\ de Neurologia de Curitiba, Curitiba, Paraná, Brazil \\ 2 Departament of Neuropathology, Instituto de Neurologia de \\ Curitiba, Paraná, Brazil \\ Departmento de Neurocirurgia, Setor de Neuro-oncologia, Instituto \\ de Neurologia de Curitiba, Rua Jeremias Maciel Perretto 300-Campo \\ Comprido, Curitiba, Paraná, CEP: 81210-310, Brasil \\ (e-mail: erasmo-inc@uol.com.br).
}

Arq Bras Neurocir 2022;41(1):e35-e42.

\begin{abstract}
Keywords

- 5-aminolevulinic acid

- brain cancer

- extent of resection

Introduction Fluorescence guidance with 5-aminolevulinic acid (5-ALA) is a safe and reliable tool in total gross resection of intracranial tumors, especially malignant gliomas and cases of metastasis. In the present retrospective study, we have analyzed 5-ALA-induced fluorescence findings in different central nervous system (CNS) lesions to expand the indications of its use in differential diagnoses.

Objectives To describe the indications and results of 5-ALA fluorescence in a series of 255 cases.

Methods In 255 consecutive cases, we recorded age, gender, intraoperative 5-ALA fluorescence tumor response, and 5-ALA postresection status, as well the complications related to the method. Postresection was classified as '5-ALA free' or '5-ALA residual'. The diagnosis of histopathological tumor was established according to the current classification of the World Health Organization (WHO).

Results There were 195 (76.4\%) 5-ALA positive cases, 124 (63.5\%) of whom underwent the '5-ALA free' resection. The findings in the positive cases were: $135 \mathrm{gliomas}$ of all grades; 19 meningiomas; 4 hemangioblastomas; 1 solitary fibrous tumor; 27 metastases; 2 diffuse large B cell lymphomas; 2 cases of radionecrosis; 1 inflammatory disease; 2 cases of gliosis; 1 cysticercosis; and 1 immunoglobulin G4-related disease.
\end{abstract}

received

March 25, 2021

accepted

June 16, 2021

published online

January 4, 2022
DOI https://doi.org/

10.1055/s-0041-1739272. ISSN 0103-5355.

\footnotetext{
(c) 2022. Sociedade Brasileira de Neurocirurgia. All rights reserved. This is an open access article published by Thieme under the terms of the Creative Commons Attribution-NonDerivative-NonCommercial-License, permitting copying and reproduction so long as the original work is given appropriate credit. Contents may not be used for commercial purposes, or adapted, remixed, transformed or built upon. (https://creativecommons.org/ licenses/by-nc-nd/4.0/)

Thieme Revinter Publicações Ltda., Rua do Matoso 170, Rio de Janeiro, RJ, CEP 20270-135, Brazil
} 


\section{Resumo}

\author{
Palavras-chave \\ - ácido 5- \\ aminolevulínico \\ - câncer no cérebro \\ - extensão de \\ ressecção
}

Conclusion Fluorescence with 5-ALA can be observed in lesions other than malignant gliomas or metastases, including meningiomas, hemangioblastomas, pilocytic astrocytomas, and lymphomas. Although there is need for further evidence for the use of 5ALA beyond high-grade gliomas, it may be a safe and reliable tool to improve resection in positive tumors or to guide the histopathologic analysis in biopsies.

Introdução A fluorescência com ácido 5-aminolevulínico (5-ALA) é uma ferramenta segura e confiável para a ressecção total de tumores intracranianos, especialmente gliomas malignos e casos de metástase. Neste estudo retrospectivo, analisamos os achados de fluorescência induzida por 5-ALA em diferentes lesões do sistema nervoso central (SNC), visando ampliar as indicações de seu uso no diagnóstico diferencial.

Objetivos Descrever as indicações e resultados da fluorescência com 5-ALA em uma série de 255 casos.

Métodos Em 255 casos consecutivos, registramos idade, sexo, resposta tumoral de fluorescência intraoperatória com 5-ALA, e status de 5-ALA pós-ressecção, bem como as complicações relacionadas ao método. A pós-ressecção foi graduada como " 5 -ALA livre" ou "5-ALA residual". O diagnóstico histopatológico foi estabelecido de acordo com a classificação atual da Organização Mundial de Saúde (OMS).

Resultados Houve 195 (76.4\%) casos 5-ALA positivos, 124 (63,5\%) dos quais foram submetidos a ressecção "5-ALA livre". Os achados nos casos positivos foram: 135 gliomas; 19 meningiomas; 4 hemangioblastomas; 1 tumor fibroso solitário; 27 metástases; 2 linfomas difusos de grandes células B; 2 radionecroses; 1 doença inflamatória; 2 glioses; 1 cisticercose; e 1 doença relacionada à imunoglobulina G4.

Conclusões Fluorescência com 5-ALA pode ser observada em outras lesões além de gliomas malignos ou metástases, incluindo meningiomas, hemangioblastomas, astrocitomas pilocíticos, e linfomas. Embora haja necessidade de mais evidências para o uso de 5-ALA que não em casos de gliomas de alto grau, sua aplicação pode ser segura e confiável para melhorar a ressecção de tumores positivos ou orientar a análise histopatológica em biópsias.

\section{Introduction}

5-aminolevulinic acid (5-ALA) is the sole precursor of the non-protein heme constituent of hemoglobin. Once biosynthesized, it is transformed in cytosol until it gets converted to protoporphyrin IX (PpIX) inside the mitochondria. The accumulation of PpIX in certain lesions helps to distinguish neoplastic from normal tissue under blue light filter for photodynamic detection. ${ }^{1}$

Neurosurgical microscopes coupled with a switchable white and violet-blue light source excite the PpIX, enabling the visualization of tumor fluorescence, in red, and normal tissue, non-fluorescent, in blue. ${ }^{2}$ Applications of 5-ALA in brain tumor surgery have been described in the last two decades, and have been stimulated by increasing resection areas with better progression-free survival (PFS), especially in malignant intracranial lesions, such as glioblastomas and metastases. $^{3-5}$ These promising results evolved to distinct applications in recent laboratory and translational studies. ${ }^{6-11}$ Over the years, 5-ALA has also been introduced in the treatment of other intracranial tumors, ${ }^{6-11}$ especially in cases of metastases ${ }^{6-8}$ and meningiomas. ${ }^{9-11}$
Routinely used in Europe, Asia and Australia, 5-ALA was approved by the United States Food and Drug Administration (FDA) in 2017. ${ }^{12-16}$ In Brazil, it is approved by the Brazilian Patent Office and National Sanitary Vigilance Agency (Agência Nacional de Vigilância Sanitária, ANVISA, in Portuguese) under registry number $80046190162 .{ }^{17}$

Since 2015 , a few articles ${ }^{18-20}$ have reported the initial Latin America experience with 5-ALA fluorescence brain surgery. This emerging tool has become standard to maximize brain tumor removal, enabling real-time guidance through the tissue with surgeon's constant interrogation about what is normal tissue and what is infiltrated brain. With other concomitant intraoperative tools, such as neuronavigation, intraoperative magnetic resonance imaging (MRI), awake surgery, and electrophysiological monitoring, 5-ALA optimized the surgical treatment in neuro-oncology, providing safer and better outcomes.

The purpose of the present article is to describe the application of 5-ALA fluorescence-guided surgery to expand its indications beyond malignant gliomas and metastases. 


\section{Methods}

Between November 2015 and May 2020, at our institution, there were 255 consecutive cases of central nervous system tumors in which the patients underwent 5-ALA fluorescenceguided surgery. All patients had a preoperative Karnofsky Performance Scale (KPS) $>70 \%$ at the time of the procedure. 5 - aminolevulinic acid was administered in selected suspected cases of gliomas, metastases and meningiomas. The present study complies with ethical standards, and informed consent was obtained from patients or their relatives.

\section{Preoperative Care}

Every patient underwent an imaging evaluation with magnetic resonance imaging (MRI), spectroscopy, and perfusion. The indications for advanced MRI varied according to tumor location and diagnostic hypothesis. Tractography and functional MRI were performed for tumors in eloquent regions. Three hours prior surgery, 5-ALA was administered orally, amounting to a dose of $20 \mathrm{mg} / \mathrm{kg}$ dissolved in $50 \mathrm{~mL}$ of drinking water.

\section{Intraoperative Care}

Patient care (anesthesia induction, positioning etc.) was as routine. Intraoperative pathology were performed for every case. Image guidance with neuronavigation was used in all intracranial tumors. Electrophysiological stimulation and monitoring or awake surgery were also performed for tumors in eloquent areas. The OPMI PENTERO 800 (Carl Zeiss Meditec AG, Jena, Germany) was the neurosurgical microscope used in the present series.

During the corticotomy, switching from white to blue excitation light showed cortical and/or subcortical tumor infiltration and the limits of the 5-ALA positiveness. In cases of 5-ALA-negative tumors, intraoperative MRI (iMRI) was available. Fluorescence intraoperative findings were classified in three zones: non-fluorescent tissue - usually normal brain, necrosis, or 5-ALA negative tumors, in blue; strong 5ALA fluorescence - in red, showing positive solid tumors; and poor 5-ALA fluorescence - in pink, showing infiltrating tissue. Intraoperative pathology examinations were performed in each fluorescent zone.

At the end of surgery, the cases in which all tissue with visible strong and poor fluorescence were classified as '5ALA free'. Cases of residual tumors were classified as ' 5 -ALA residual', and the decision was based on the risks of postoperative deficits. The final diagnosis was established according to the 2016 World Health Organization (WHO) criteria.

\section{Postoperative Care}

All patients underwent postoperative MRI scans in the first 24 hours. The imaging findings were evaluated by the neuroradiology team.

\section{Results}

There were 255 cases in 236 patients ranging from 3 to 90 years of age who underwent 5-ALA fluorescence-guided surgery. The sample was composed of 99 women and 137 men. A total of 19 patients with high-grade gliomas underwent surgery in two different occasions. - Table 1 summarizes the results based on the final diagnosis and the 5-ALA removal status. - Figs. 1 to 7 show illustrative cases of specific diseases.

Complications due to 5-ALA administration: one male patient with history of drug addiction presented cardiac arrhythmia two hours after the administration of 5-ALA, prior to anesthetic induction. Surgery was suspended and performed a week later, without additional administrations of 5-ALA. This case was excluded from the 5-ALA response results. No other complication associated with 5-ALA was found in the present series.

5-ALA response: there were 195 (76.4\%) 5-ALA positive and 60 (23.6\%) 5-ALA negative cases.

5-ALA removal status: 124 (63.5\%) of the 195 positive cases underwent complete removal based on fluorescence ('5-ALA free'); in 57 (29.2\%) cases, the patients underwent ' 5 ALA residual' resection; and there were 14 cases (7.3\%) of biopsies with 5-ALA positivity.

Astrocytic and oligodendroglial tumors: there were 4 pilocytic astrocytomas: 2 (50\%) negative and 2 (50\%) positive for 5-ALA. Regarding diffuse tumors, there were 24 grade-II astrocytomas: 6 (25\%) 5-ALA positive, 4 of which with heterogeneous fluorescence varying between poor and strong, and 18 (75\%) 5-ALA negative; 7 oligodendrogliomas: 6 (85.7\%) negative and 1 (14.3\%) 5-ALA homogenously positive. As for anaplastic tumors, there were 6 grade-III astrocytomas: 3 (50\%) positive (in 2 of these cases, fluorescence was found in an anaplastic isle), and $3(50 \%)$ negative; 10 anaplastic oligodendrogliomas: $9(90 \%)$ positive (3 with heterogeneous fluorescence varying between poor and strong), and 1 (10\%) negative. There were 108 glioblastomas: $4(3.8 \%)$ negative, and 104 (96.2\%) positive, 18 of which cases had heterogeneous fluorescence due to necrosis (negative) and positivity variation between poor and strong. Moreover, three $(2.8 \%)$ cases 5-ALA positive glioblastomas were giantcell variants.

Ependymal tumors: there were 3 grade-I subependymomas: $2(66.6 \%)$ negative cases and $1(33.4 \%)$ positive case; 8 grade-II ependymomas: 3 (37.5\%) negative, and 5 (62.5\%) positive ( 1 of which with heterogeneous fluorescence due to a subependymal component [poor] mixed with an ependymal [strong] component). There was one case of an anaplastic ependymoma that was positive.

Meningiomas: there wer 17 cases of grade-I and 2 cases grade-II meningioma, all of them (100\%) positive. In 2 (10.5\%) of the cases, there was heterogenous fluorescence due to calcification zones (pink).

Mesenchymal non-meningothelial tumors: there were 4 hemangioblastomas and 1 solitary fibrous tumor, all of them positive.

Metastases: there were 35 cases, 8 (22.8\%) negative, and $27(77.2 \%)$ positive. There were 24 adenocarcinomas (10 in the lungs, 12 in the breasts, 1 in the thyroid, and 1 in the colon): $4(16.6 \%)$ negative, and $20(83.4 \%)$ positive; 5 melanomas: $3(60 \%)$ negative, and $2(40 \%)$ positive. There were 6 
Extending the Indications of 5-Aminolevulinic Acid for Fluorescence-Guided Surgery for Different Central Nervous 38 System Tumors Silva Jr. et al.

Table 1 Tumors classified by types, 5-aminolevulinic acid (5-ALA) response, and removal status

\begin{tabular}{|c|c|c|c|}
\hline Diagnosis & Total & 5-ALA positive & 5-ALA removal \\
\hline \multicolumn{4}{|l|}{ Astrocytic and oligodendroglial } \\
\hline Pilocytic astrocytoma, grade I & 4 & 2 & 2 5-ALA free \\
\hline Difuse astrocytoma, grade II & 24 & 6 & 4 5-ALA free \\
\hline Oligodendroglioma, grade II & 7 & 1 & 15 -ALA free \\
\hline Anaplastic astrocytoma, grade III & 6 & 3 & 1 5-ALA free \\
\hline Anaplastic oligodendroglioma, grade III & 10 & 9 & 7 5-ALA free \\
\hline Glioblastoma, grade IV & 108 & 104 & 59 5-ALA free, 7 biopsies \\
\hline Astroblastoma & 1 & 1 & 1 5-ALA free \\
\hline Diffuse midline glioma & 1 & 1 & 1 biopsy \\
\hline \multicolumn{4}{|l|}{ Ependymal } \\
\hline Subependymoma, grade I & 3 & 1 & 15 -ALA free \\
\hline Ependymoma, grade II & 8 & 5 & 3 5-ALA free \\
\hline Anaplastic ependymoma, grade III & 1 & 1 & 1 5-ALA free \\
\hline \multicolumn{4}{|l|}{ Mixed neuronal-glial } \\
\hline Ganglioglioma & 4 & 0 & - \\
\hline Rosette-forming glioneuronal tumor & 1 & 0 & - \\
\hline Dysplastic cerebellar gangliocytoma & 1 & 0 & - \\
\hline \multicolumn{4}{|l|}{ Meningiomas } \\
\hline Meningioma, grade I & 17 & 17 & 16 5-ALA free \\
\hline Atypical Meningioma, grade II & 2 & 2 & 2 5-ALA free \\
\hline \multicolumn{4}{|l|}{ Mesenchymal non-meningothelial } \\
\hline Hemangioblastoma & 4 & 4 & 4 5-ALA free \\
\hline Solitary fibrous tumor & 1 & 1 & 15 -ALA free \\
\hline \multicolumn{4}{|l|}{ Metastatic } \\
\hline Adenocarcinoma, breast & 10 & 6 & 4 5-ALA free \\
\hline Adenocarcinoma, lung & 12 & 12 & 7 5-ALA free/2 biopsies \\
\hline Melanoma & 5 & 2 & 2 5-ALA free \\
\hline Small cells, kidney & 2 & 1 & 1 5-ALA free \\
\hline Adenocarcinoma, colon & 1 & 1 & 1 5-ALA free \\
\hline Adenocarcinoma, thyroid & 1 & 1 & 15 -ALA free \\
\hline Adenoneuroendocrine carcinoma & 3 & 3 & 1 5-ALA free/1 biopsy \\
\hline Carcinoid tumor, lung & 1 & 1 & 1 5-ALA free \\
\hline \multicolumn{4}{|l|}{ Other tumors } \\
\hline Diffuse large B-cell lymphoma & 3 & 2 & 1 5-ALA free, 1 biopsy \\
\hline Schwannoma & 1 & 0 & - \\
\hline \multicolumn{4}{|l|}{ Non-neoplastic } \\
\hline Radionecrosis & 2 & 2 & 2 5-ALA residual \\
\hline Inflammatory & 2 & 1 & 1 5-ALA free \\
\hline Gliosis & 6 & 2 & 2 5-ALA residual, 1 biopsy \\
\hline Cysticercosis & 1 & 1 & 1 5-ALA free \\
\hline Demyelinating disease & 2 & 1 & 1 biopsy \\
\hline
\end{tabular}



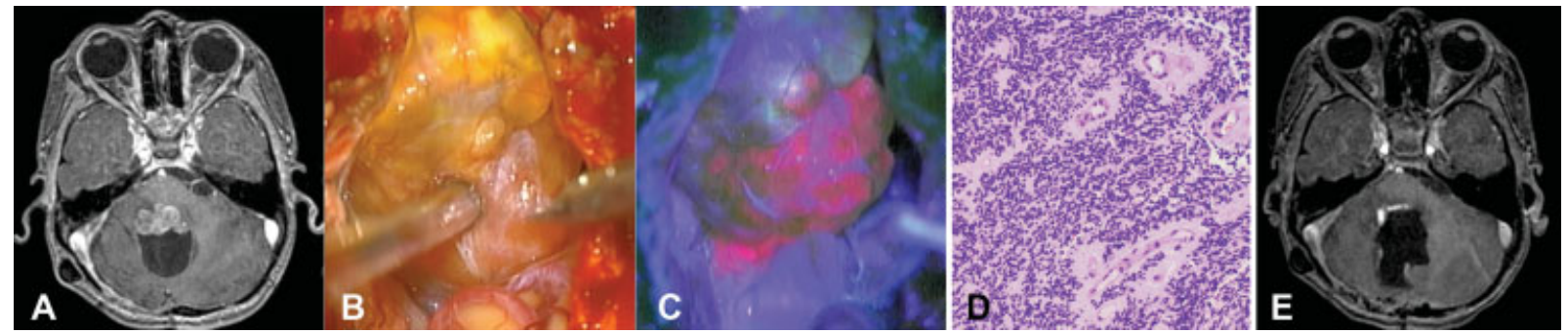

Fig. 1 Illustrative case of a grade-II ependymoma: (A) preoperative magnetic resonance imaging (MRI) scan. (B) intraoperative finding; (C) positivity for 5-aminolevulinic acid (5-ALA); (D) histopathological finding; (E) postoperative MRI.
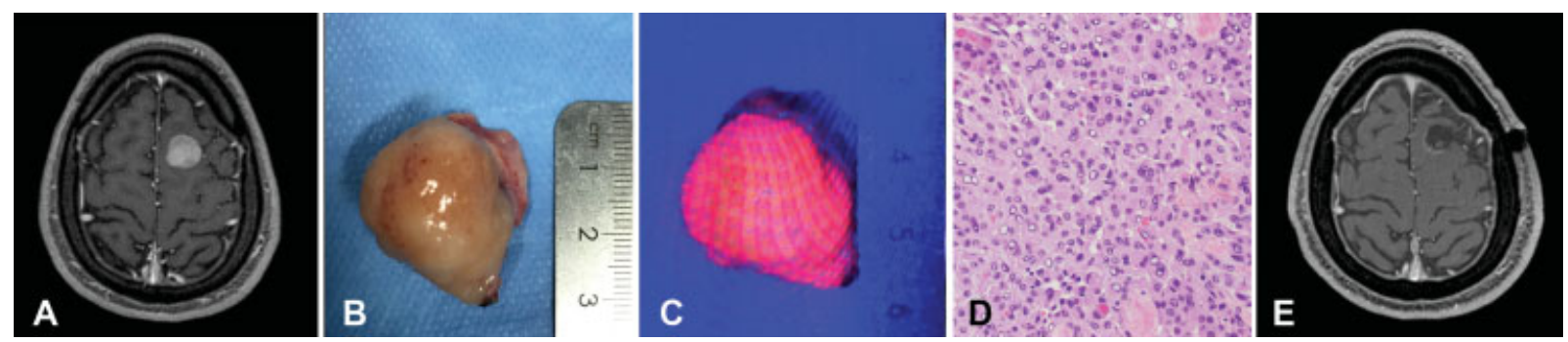

Fig. 2 Illustrative case of a grade-I meningioma: (A) preoperative MRI; (B) intraoperative finding; (C) 5-ALA positivity; (D) histopathological finding; (E) postoperative MRI.
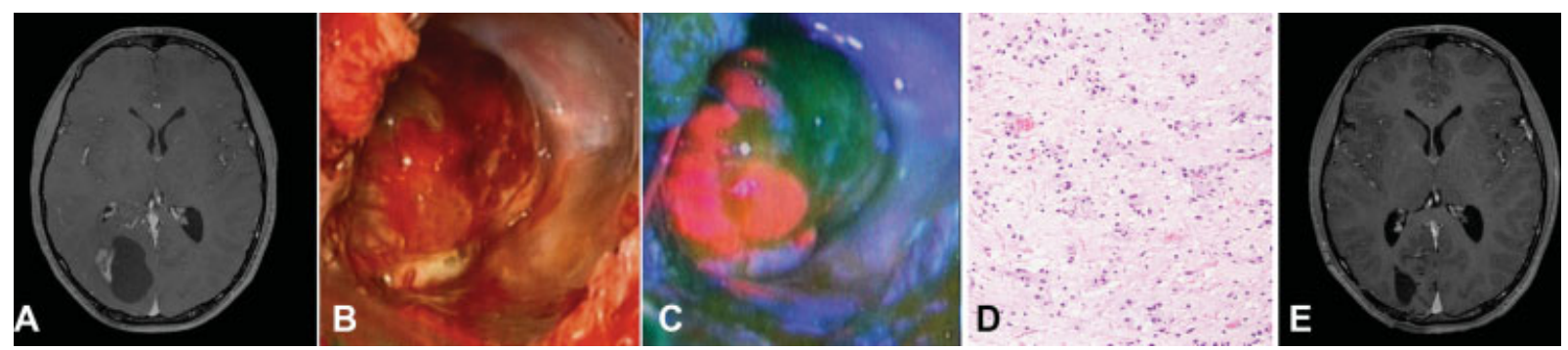

Fig. 3 Illustrative case of a pilocytic astrocytoma: (A) preoperative MRI; (B) intraoperative finding; (C) 5-ALA positivity; (D) histopathological finding; (E) postoperative MRI.
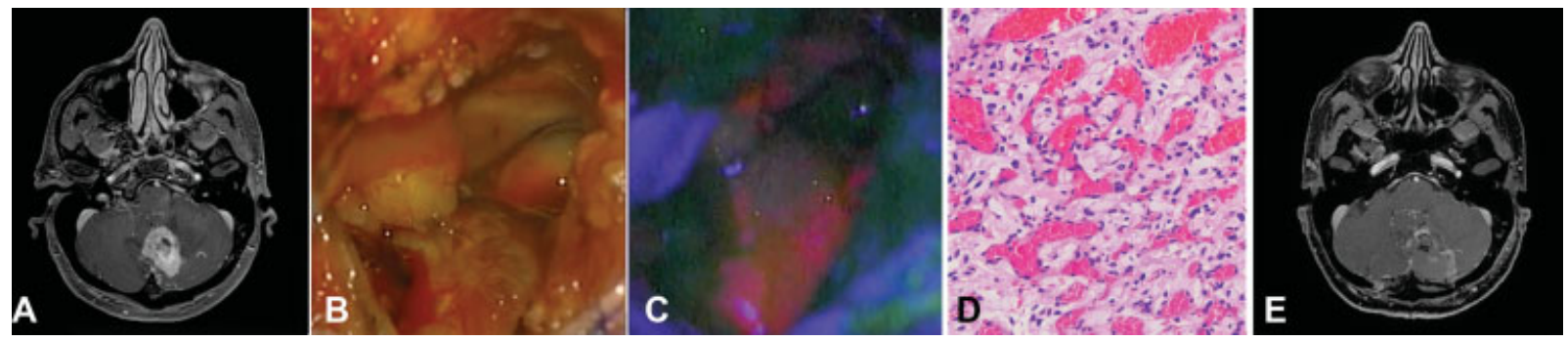

Fig. 4 Illustrative case of a hemangioblastoma: (A) preoperative MRI; (B) intraoperative finding; (C) 5-ALA positivity; (D) histopathological finding; (E) postoperative MRI.
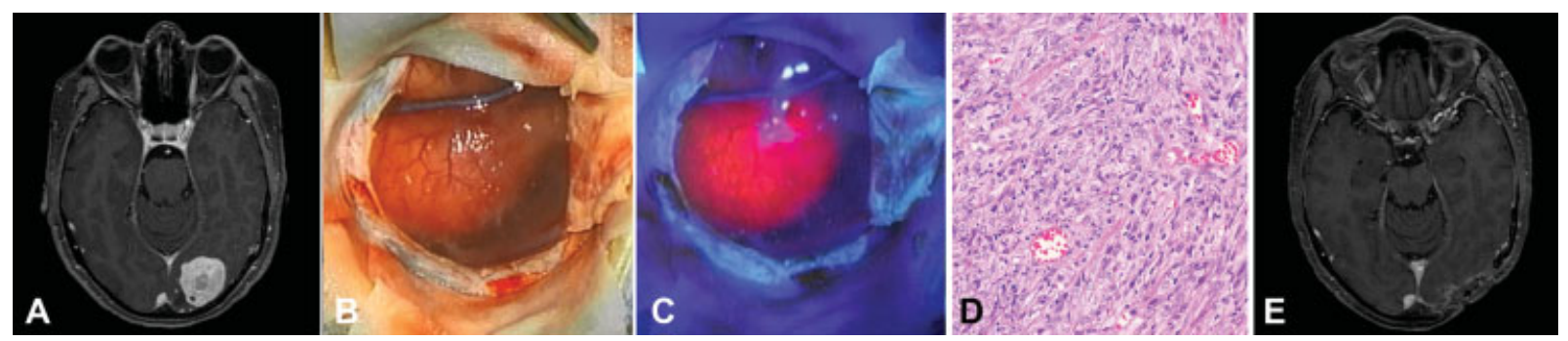

Fig. 5 Illustrative case of Solitary fibrous tumor: (A) preoperative MRI; (B) intraoperative finding; (C) 5-ALA positivity; (D) histopathological finding; (E) postoperative MRI. 

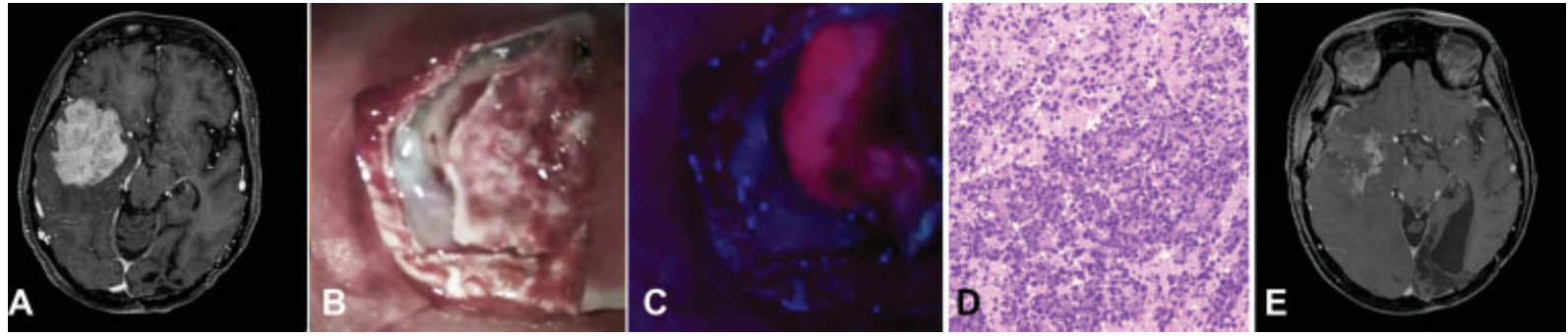

Fig. 6 Illustrative case of a diffuse large B-cell lymphoma: (A) preoperative MRI; (B) intraoperative finding; (C) 5-ALA positivity; (D) histopathological finding; (E) postoperative MRI.
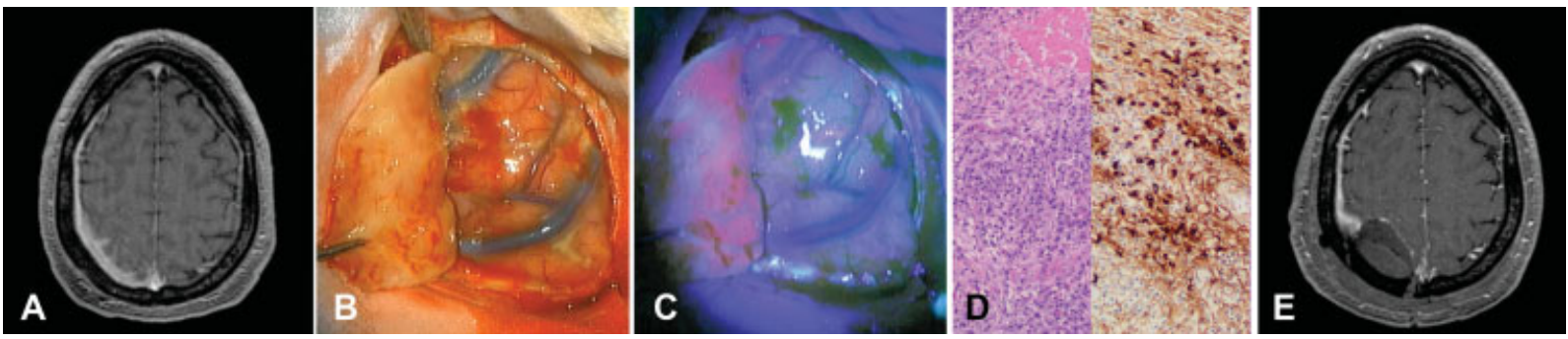

Fig. 7 Illustrative case of immunoglobulin G4-related disease: (A) preoperative MRI; (B) intraoperative finding; (C) 5-ALA positivity; (D) histopathological finding (left) with immunochemistry (right); (E) postoperative MRI.

other cases, which included 2 cases of small-cell carcinoma of the kidney ( 1 positive case and 1 negative), 1 carcinoid lung tumor, and 3 cases of mixed adeno-neuroendocrine carcinoma (all of them positive). Heterogeneous fluorescence varying from 'red to pink' was found in three (15\%) adenocarcinomas.

Diffuse large B-cell lymphomas: 2 (66.7\%) out of the 3 cases were positive, 1 of which had heterogeneous fluorescence varying between poor and strong.

Non-neoplastic diseases: there were 7 cases of unusual lesions; they were all positive, and included radionecrosis (2 cases with heterogenous fluorescence), unspecific inflammatory disease ( 1 case), gliosis ( 2 cases with heterogeneous fluorescence), cysticercosis (1 case) and immunoglobulin G4-related disease ( 1 case, with pink fluorescence).

\section{Discussion}

A natural compound, 5-ALA is metabolized via the heme biosynthetic pathway to produce PpIX. Under fluorescent blue light, the PpIX stored in malignant lesions is distinguishable from normal brain tissue and enhances the intraoperative guidance for tumor removal. The intensity of the fluorescence predicts the degree of tumor cellularity. ${ }^{3-5}$ The optimal safe fluorescence was produced with $20 \mathrm{mg} / \mathrm{kg}$ by oral administration 4 to 6 hours prior to tumor removal. No fluorescence can be visualized with a dose of $0.2 \mathrm{mg} / \mathrm{kg}$, and doses higher than $20 \mathrm{mg} / \mathrm{kg}$ do not enhance fluorescence. ${ }^{21}$

In 1998, Stummer et al. ${ }^{1,2}$ reported the first series of 270 cases of 5-ALA fluorescence-guided surgery for glioblastoma. In 2006, a randomized phase-III study confirmed 5-ALA as a reliable adjuvant tool to achieve gross total removal of high-grade gliomas, with acomplete resection in $65 \%$ of 5 -
ALA cases versus $36 \%$ of the patients who underent conventional microsurgery; ${ }^{22}$ consequently, PFS was higher in the 5-ALA group. ${ }^{23}$ In 2007, the European Medicines Agency (EMA) approved 5-ALA, but it was only approved by the FDA in 2017 for use as an intraoperative optical imaging agent in patients with suspected high-grade gliomas. ${ }^{12}$ The delayed FDA approval was due to the conceptualization of 5-ALA as a therapeutic tool, not as an intraoperative imaging tool. Curiously, in 2004, Brazil's ANVISA approved 5-ALA as a dye to be applied on human subjects under registry number 80046190162. ${ }^{17}$

The first cases of 5-ALA fluorescence-guided surgery for intracranial tumors in Latin America were reported in 2018. ${ }^{18,19}$ Before that, neuronavigation, intraoperative MRI, and serial biopsy were the tools available to aid in maximal safe resections. ${ }^{24}$ These techniques remain extremely relevant in cases in which fluorescence is negative.

Although the use of 5-ALA in the surgical resection of high-grade gliomas and cases of metastasis has been widely documented in the literature, ${ }^{6-11}$ consistent findings of fluorescence have been reported regarding other tumors, including benign and non-neoplastic lesions. ${ }^{3,4}$ There are few available articles ${ }^{29,33,37}$ describing the use of 5-ALA fluorescence in those differential diagnoses.

For suspected low-grade gliomas or intra-axial tumors without contrast enhancement, the indicarion of 5-ALA fluorescence can be based on preoperative images suggesting anaplastic 'hot areas' on MRI perfusion. These anaplastic foci may be identified during resection by the accumulation of fluorescence and by a separate histopathological analysis. A shorter period may be expected for malignant transformation in patients with fluorescent low-grade gliomas. ${ }^{25,26}$ In the present article, 6 (25\%) of the 24 confirmed cases of grade-II 
astrocytoma, and 1 (14.2\%) of the 7 cases of oligodendroglioma, were 5-ALA positive. These patients had a minimum follow-up of 2 years, and showed no signs of disease progression or differentiation until now. In contrast, of the 12 cases of 5-ALA positive grade-III astrocytic (3 cases) and oligodendroglial (9 cases) lesions, 2 (16.6\%) had their final had their final diagnosis due to the finding of an anaplastic focus positive for 5-ALA. In both cases, there were preoperative images without contrast enhancement with hot spots on perfusion. The use of 5-ALA optimized tissue sampling for the histopathological evaluation. In the present series, the isocitrate dehydrogenase 1 (IDH1) status showed no relationship with 5-ALA positivity, corroborating the literature findings. ${ }^{26}$

In high-grade gliomas, especially glioblastomas, 5-ALA fluorescence appears to be $>80 \%$ positive, with high sensitivity and positive predictive value. ${ }^{13,27}$ High-grade gliomas are the main and major indication for use of this method. In the present series, of 124 high-grade gliomas, 116 (93.6\%) were 5ALA positive, with $96.3 \%$ of glioblastomas and $75 \%$ of anaplastic gliomas. There were 42 (36.2\%) cases cases high-grade glioma that were '5-ALA residual' due to infiltration of eloquent areas. Previous adjuvant treatments, such as radiation and chemotherapy, in recurrent malignant tumors seem to not decrease the fluorescence response, although false-positive fluorescence can be observed more frequently. ${ }^{15}$ of 19 cases submitted to reoperation with 5-ALA fluorescence, 2 (10.5\%) presented presented radionecrosis despite heterogeneous positivity, ranging from negative to strongly positive zones.

There are few descriptions of 5-ALA fluorescence for pilocytic astrocytomas in pediatric patients, showing positiveness in $53 \%$ of the cases. ${ }^{28,29}$ In the present series, 2 (50\%) of 4 cases were 5-ALA positive, both appearing as a cystic mass with a mural nodule. Fluorescence was especially helpful in the final inspection for residual lesions.

Schwake et al. ${ }^{29}$ described $71 \%$ and $80 \%$ of 5 -ALA positivity in grade-III and -II ependymomas respectively. In the present study, out of 9 cases, 6 (66.7\%) were positive, 1 of which was grade III. There was also 1 (33.3\%) case in 3 of a 5ALA positive subependymoma. Several articles ${ }^{30-32}$ evaluated the utility of 5-ALA-guided removal of spinal lesions, finding positive fluorescence to be reliable especially in ependymomas and meningiomas.

In intracranial meningiomas, 5-ALA positive fluorescence may range from $77 \%$ to $96 \%$, ${ }^{9,11}$ with intratumoral fluorescence homogeneity higher than $75 \%$. In the present series, $100 \%$ of the 19 cases of meningioma were 5-ALA positive, with no apparent correlation with the histopathological grade. The method was useful to visualize dural and osseous infiltrations not visible under the white light of the microscope, previously described with $100 \%$ specificity and $89 \%$ sensitivity. ${ }^{10}$ This reinforces a possible benefit of 5-ALA in optimizing the resection result in conjunction with the Simpson removal classification. The long term follow-up of these patients will be the object of further studies.

Like pilocytic astrocytomas, hemangioblastomas can also show positive fluorescence in mural nodules. ${ }^{33} 100 \%$ of the 4 cases cases described in the present article were 5-ALA positive, and the method helped achieve complete removal.
Large series ${ }^{6,7}$ of intracranial metastases show 5-ALA positivity ranging between $28 \%$ and $81.8 \%$. In the present article, $77.2 \%$ of the cases were 5-ALA positive, with higher response in adenocarcinomas (83.3\%) than in melanomas (40\%). Fluorescence was useful to help define the possible cortical and subcortical limits of resection, although not necessarily containing metastatic infiltration. ${ }^{4}$ Heterogeneous positivity was found in $10(28.5 \%)$ of the 5-ALA positive metastases, ranging from poor to strong fluorescent zones. Although expected in cases with previous adjuvant treatment such as chemotherapy and irradiation, ${ }^{6}$ we found no relationship in the present series. The use of 5-ALA was particularly efficient in cases in which 'en bloc' removal - in opposition to 'piecemeal resection' - was possible, given the possibility of safe oncological margins.

Due to the expected difficulty in the differential radiological diagnosis between high-grade glioma and primary central nervous system lymphoma, 5-ALA seems to be a useful tool in stereotaxic biopsies, optimizing tumor sampling based in positivity. ${ }^{34,35}$ In a series of 41 biopsies, Yamamoto et al. ${ }^{36}$ observed $82.9 \%$ of 5-ALA positivity in Ppimary central nervous system lymphomas. Evers et al. ${ }^{37}$ reported 8 of 11 patients (73\%) with strong homogenous fluorescence as well. In the present series, there were 14 5-ALA positive biopsies that aided in the intraoperative analysis. Samples were collected from both positive and negative areas. Intraoperative histopathology confirmed anomalous tissue in all positive fragments. It was especially helpful in non-neoplastic lesions, such as a case of immunoglobulin G4-related disease and an intracranial cysticercoid cyst.

In our experience, the use of 5-ALA has been safely extended to any contrast-enhanced tumor of the central nervous system, except for schwannomas. Its application to benign lesions such as pilocytic astrocytomas, hemangioblastomas, and meningiomas may have relevance in the final inspection of the surgical cavity, avoiding any residual fluorescence. Also, 5-ALA fluorescence seems to be especially interesting in atypical or challenging diagnoses, reinforcing its high sensitivity. These cases should be the subject of future studies.

\section{Conclusion}

Although more evidence is needed, the indications for 5-ALA fluorescence-guided surgery may be safely expanded based on the expected positive fluorescence. Its applications include tumors with potentially positive fluorescence other than malignant gliomas or metastases, optimizing removal and the histopathologic diagnosis.

Conflict of Interests

The authors have no conflict of interests to declare.

\section{References}

1 Stummer W, Stepp H, Möller G, Ehrhardt A, Leonhard M, Reulen HJ. Technical principles for protoporphyrin-IX-fluorescence guided microsurgical resection of malignant glioma tissue. Acta Neurochir (Wien) 1998;140(10):995-1000 
2 Stummer W, Stocker S, Wagner S, et al. Intraoperative detection of malignant gliomas by 5 -aminolevulinic acid-induced porphyrin fluorescence. Neurosurgery 1998;42(03):518-525, discussion 525-526

3 Ewelt C, Nemes A, Senner V, et al. Fluorescence in neurosurgery: Its diagnostic and therapeutic use. Review of the literature. J Photochem Photobiol B 2015;148:302-309

4 Ferraro N, Barbarite E, Albert TR, et al. The role of 5-aminolevulinic acid in brain tumor surgery: a systematic review. Neurosurg Rev 2016;39(04):545-555

5 Senders JT, Muskens IS, Schnoor R, et al. Agents for fluorescenceguided glioma surgery: a systematic review of preclinical and clinical results. Acta Neurochir (Wien) 2017;159(01):151-167

6 Kamp MA, Grosser P, Felsberg J, et al. 5-aminolevulinic acid (5ALA)-induced fluorescence in intracerebral metastases: a retrospective study. Acta Neurochir (Wien) 2012;154(02):223-228, discussion 228

7 Kamp MA, Munoz-Bendix C, Mijderwijk HJ, et al. Is 5-ALA fluorescence of cerebral metastases a prognostic factor for local recurrence and overall survival? J Neurooncol 2019;141(03): 547-553

8 Knipps J, Fischer I, Neumann LM, et al. Quantification of PpIXfluorescence of cerebral metastases: a pilot study. Clin Exp Metastasis 2019;36(05):467-475

9 Millesi M, Kiesel B, Mischkulnig M, et al. Analysis of the surgical benefits of 5-ALA-induced fluorescence in intracranial meningiomas: experience in 204 meningiomas. J Neurosurg 2016;125 (06):1408-1419

10 Rustemi O, Della Puppa A. Hyperostosis and osteolysis in skull base meningiomas: are different nuances of 5-ALA fluorescence related to different invasion patterns? J Neurosurg Sci 2019;63 (04):484-485

11 Valdes PA, Millesi M, Widhalm G, Roberts DW. 5-aminolevulinic acid induced protoporphyrin IX (ALA-PpIX) fluorescence guidance in meningioma surgery. J Neurooncol 2019;141(03): 555-565

12 Hadjipanayis CG, Stummer W. 5-ALA and FDA approval for glioma surgery. J Neurooncol 2019;141(03):479-486

13 Haider SA, Lim S, Kalkanis SN, Lee IY. The impact of 5-aminolevulinic acid on extent of resection in newly diagnosed high grade gliomas: a systematic review and single institutional experience. J Neurooncol 2019;141(03):507-515

14 Lakomkin N, Hadjipanayis CG. Fluorescence-guided surgery for high-grade gliomas. J Surg Oncol 2018;118(02):356-361

15 Chohan MO, Berger MS. 5-Aminolevulinic acid fluorescence guided surgery for recurrent high-grade gliomas. J Neurooncol 2019;141(03):517-522

16 Halani SH, Adamson DC. Clinical utility of 5-aminolevulinic acid $\mathrm{HCl}$ to better visualize and more completely remove gliomas. OncoTargets Ther 2016;9:5629-5642

17 Agência Nacional de Vigilância Sanitária Retificação de Publicação em Produtos para Saúde. Brasília, DF: Diário oficial da União; June 10, 2014. Suppl 109. 8419

18 Ramina R, Silva Júnior EB, Constanzo F, Coelho Neto M. Indications of 5-Aminolevulinic Acid and Intraoperative MRI in Glioma Surgery: First Cases in Latin America in a Single Reference Center. Braz Neurosurg 2018;37(02):88-94

19 Ramina R, Da Silva Júnior EB, Coelho Neto M, Ruschel L, Navarrette F. 5-Aminolevulinic Acid-Protoporphyrin IX Fluorescence-Guided Surgery for CNS Tumors. J Bras Neurocir 2018; 27(01):13-19

20 Ruschel LG, Ramina R, da Silva EB Jr, Cavalcanti MS, Duarte JFS. 5Aminolevulinic acid fluorescence-guided surgery for spinal cord melanoma metastasis: a technical note. Acta Neurochir (Wien) 2018;160(10):1905-1908

21 Stummer W, Stepp H, Wiestler OD, Pichlmeier U. Randomized, Prospective Double-Blinded Study Comparing 3 Different Doses of 5-Aminolevulinic Acid for Fluorescence-Guided Resections of Malignant Gliomas. Neurosurgery 2017;81(02):230-239

22 Stummer W, Pichlmeier U, Meinel T, Wiestler OD, Zanella F, Reulen HJALA-Glioma Study Group. Fluorescence-guided surgery with 5-aminolevulinic acid for resection of malignant glioma: a randomised controlled multicentre phase III trial. Lancet Oncol 2006;7(05):392-401

23 Stummer W, Tonn JC, Mehdorn HM, et al; ALA-Glioma Study Group. Counterbalancing risks and gains from extended resections in malignant glioma surgery: a supplemental analysis from the randomized 5-aminolevulinic acid glioma resection study. Clinical article. J Neurosurg 2011;114(03):613-623

24 Ramina R, Coelho Neto M, Giacomelli A, et al. Optimizing costs of intraoperative magnetic resonance imaging. A series of 29 glioma cases. Acta Neurochir (Wien) 2010;152(01):27-33

25 Jaber M, Ewelt C, Wölfer J, et al. Is Visible Aminolevulinic AcidInduced Fluorescence an Independent Biomarker for Prognosis in Histologically Confirmed (World Health Organization 2016) LowGrade Gliomas? Neurosurgery 2019;84(06):1214-1224

26 Al-Tamimi YZ, Palin MS, Patankar T, et al. Low-Grade Glioma with Foci of Early Transformation Does Not Necessarily Require Adjuvant Therapy After Radical Surgical Resection. World Neurosurg 2018;110:e346-e354

27 Mansouri A, Mansouri S, Hachem LD, et al. The role of 5-aminolevulinic acid in enhancing surgery for high-grade glioma, its current boundaries, and future perspectives: A systematic review. Cancer 2016;122(16):2469-2478

28 Roth J, Constantini S. 5ALA in pediatric brain tumors is not routinely beneficial. Childs Nerv Syst 2017;33(05):787-792

29 Schwake M, Schipmann S, Müther M, Köchling M, Brentrup A, Stummer W. 5-ALA fluorescence-guided surgery in pediatric brain tumors-a systematic review. Acta Neurochir (Wien) 2019; 161(06):1099-1108

30 Eicker SO, Floeth FW, Kamp M, Steiger HJ, Hänggi D. The impact of fluorescence guidance on spinal intradural tumour surgery. Eur Spine J 2013;22(06):1394-1401

31 Millesi M, Kiesel B, Woehrer A, et al. Analysis of 5-aminolevulinic acid-induced fluorescence in 55 different spinal tumors. Neurosurg Focus 2014;36(02):1-11

32 Wainwright JV, Endo T, Cooper JB, Tominaga T, Schmidt MH. The role of 5-aminolevulinic acid in spinal tumor surgery: a review. J Neurooncol 2019;141(03):575-584

33 Utsuki S, Oka H, Sato K, Shimizu S, Suzuki S, Fujii K. Fluorescence diagnosis of tumor cells in hemangioblastoma cysts with 5aminolevulinic acid. J Neurosurg 2010;112(01):130-132

34 Widhalm G, Minchev G, Woehrer A, et al. Strong 5-aminolevulinic acid-induced fluorescence is a novel intraoperative marker for representative tissue samples in stereotactic brain tumor biopsies. Neurosurg Rev 2012;35(03):381-391, discussion 391

35 Shooman D, Belli A, Grundy PL. Image-guided frameless stereotactic biopsy without intraoperative neuropathological examination. J Neurosurg 2010;113(02):170-178

36 Yamamoto T, Ishikawa E, Miki S, et al. Photodynamic Diagnosis Using 5-Aminolevulinic Acid in 41 Biopsies for Primary Central Nervous System Lymphoma. Photochem Photobiol 2015;91(06): 1452-1457

37 Evers G, Kamp M, Warneke N, et al. 5-Aminolaevulinic AcidInduced Fluorescence in Primary Central Nervous System Lymphoma. World Neurosurg 2017;98:375-380 